\title{
Микромассивы кремниевых нанопилларов: формирование и резонансное отражение света
}

\author{
(С) Л.С. Басалаева ${ }^{1}$, Ю.В. Настаушев ${ }^{1}$, Ф.Н. Дульцев ${ }^{1,2}$, Н.В. Крыжановская ${ }^{3}$, Э.И. Моисеев ${ }^{3}$ \\ ${ }^{1}$ Институт фризики полупроводников им. А.В. Ржанова Сибирского отделения Российской академии наук, \\ 630090 Новосибирск, Россия \\ ${ }^{2}$ Новосибирский государственный университет, \\ 630090 Новосибирск, Россия \\ ${ }^{3}$ Санкт-Петербургский национальный исследовательский Академический университет Российской академии наук, \\ 194021 Санкт-Петербург, Россия \\ E-mail: basalaeva@isp.nsc.ru
}

(Получена 10 июля 2018 г. Принята к печати 21 августа 2018 г.)

\begin{abstract}
Представлены результаты исследования спектральных характеристик отражения микромассивов кремниевых нанопилларов (Si НП) в диапазоне длин волн от 400 до 1100 нм. Кремниевые нанопиллары были сформированы методом электронной литографии на негативном резисте с последующим реактивным ионным травлением через маску из резиста и $\mathrm{SiO}_{2}$ толщиной 100 нм. В спектрах отражения микромассивов нанопилларов наблюдаются минимумы, положения которых сильно зависят от диаметра нанопилларов.
\end{abstract}

DOI: 10.21883/FTP.2019.02.47101.8956

\section{1. Введение}

Микромассивы нанопилларов (от английского nanopillar - наностолбик) - это уникальные резонансные системы. Кремниевые нанопиллары ( $\mathrm{Si} \mathrm{HП}$ ) характеризуются необычными оптическими и фотоэлектрическими свойствами [1-6]. Особый интерес к этим структурам обусловлен возможностью реализации на их основе оптических фильтров и цветной печати высокого разрешения $[7,8]$. Цветной фильтр на отражение на основе субмикрометровой решетки $\mathrm{Si}$ НП имеет узкую полосу пропускания с малой чувствительностью к углу падения света [9]. Если формировать нанопиллары на гибкой подложке, можно легко настраивать и контролировать генерируемый цвет [10]. Структурный цвет $\mathrm{Si}$ НП является перспективной альтернативой пигментным красителям.

Как известно, взаимодействие оптического излучения с одиночным $\mathrm{Si}$ НП сильно зависит от его геометрических размеров (высота, диаметр). Особенно интересен случай, когда диаметр и высота $\mathrm{Si}$ НП имеют размеры в диапазоне длин волн падающего излучения. Можно управлять свойствами всей системы наноструктурированного материала на основе $\mathrm{Si} \mathrm{HП}$, изменяя размеры единичной ячейки и период в массиве. При этом единичная ячейка может состоять из одного нанопиллара, димера [11] или иметь более сложный вид. Период $\mathrm{Si}$ НП (период ячейки) является важным параметром настройки оптического отклика такой системы в случае, если период по порядку величины соответствует длине волны падающего излучения. В последнее время большое внимание уделяется исследованию резонансов Ми в диэлектрических сферах и нанодисках, но зачастую в этом случае рассматривают одиночные объекты либо массивы с периодом, бо́льшим по сравнению с длиной волны $[12,13]$.
Ранее в наших работах для создания $\mathrm{Si}$ НП использовалась методика формирования нанопилларов посредством электронно-лучевой литографии на негативном резисте с последующим реактивным ионным травлением кремния $[14,15]$. Главное преимущество данной методики - это возможность исключить дополнительное легирование $\mathrm{Si}$ НП на начальном этапе формирования структур. Мы существенно усовершенствовали методику для формирования организованных массивов $\mathrm{Si} \mathrm{HП}$ различных размеров, вида и формы [16]. В работе [17] одним из недостатков реактивного ионного травления структур через маску из резиста ma-N2403 указана малая селективность травления кремния к негативному резисту $1: 1.71$ (Si:ma-N2403). Однако мы достигаем лучшей селективности травления $[15,18]$. Дополнительная маска из $\mathrm{SiO}_{2}$ способствует существенному увеличению глубины травления и аспектного отношения формируемых структур в массивах с периодом расположения Si НП < 500 нм. В данной статье описываются особенности формирования $\mathrm{Si}$ НП через маску из негативного резиста та-N2403 толщиной 300 нм и пленку $\mathrm{SiO}_{2}$ толщиной 100 нм. Высота сформированных $\mathrm{Si} \mathrm{HП}$ составила 350 нм. Также исследуются спектральные характеристики отражения сформированных структур.

\section{2. Эксперимент}

В данной работе упорядоченные массивы Si HП формируются с использованием электронной литографии на негативном резисте ma-N2403 и реактивного ионного травления последовательно через маску из негативного резиста и через маску из $\mathrm{SiO}_{2}$. Общая схема формирования структур приводится на рис. $1, a$. В качестве исходной подложки использовались пластины кремния $\langle 100\rangle$, покрытые пленкой $\mathrm{SiO}_{2}$ толщиной 100 нм. Пленку 
негативного резиста толщиной 300 нм наносили методом центрифугирования после предварительной перекисноаммиачной обработки поверхности (центрифуга Spin 150 Wafer spinner).

Программными средствами задавался необходимый вид структур в виде набора массивов точек площадью 100 мкм $^{2}$. Экспонирование резиста в пучке электронов проводилось с ускоряющим напряжением 20 кВ при токе пучка 28 пА. Экспонирование образцов осуществлялось на установке электронно-лучевой литографии Pioneer (Raith GmbH). Доза экспонирования на точку варьировалась от массива к массиву. Проявление изображе-
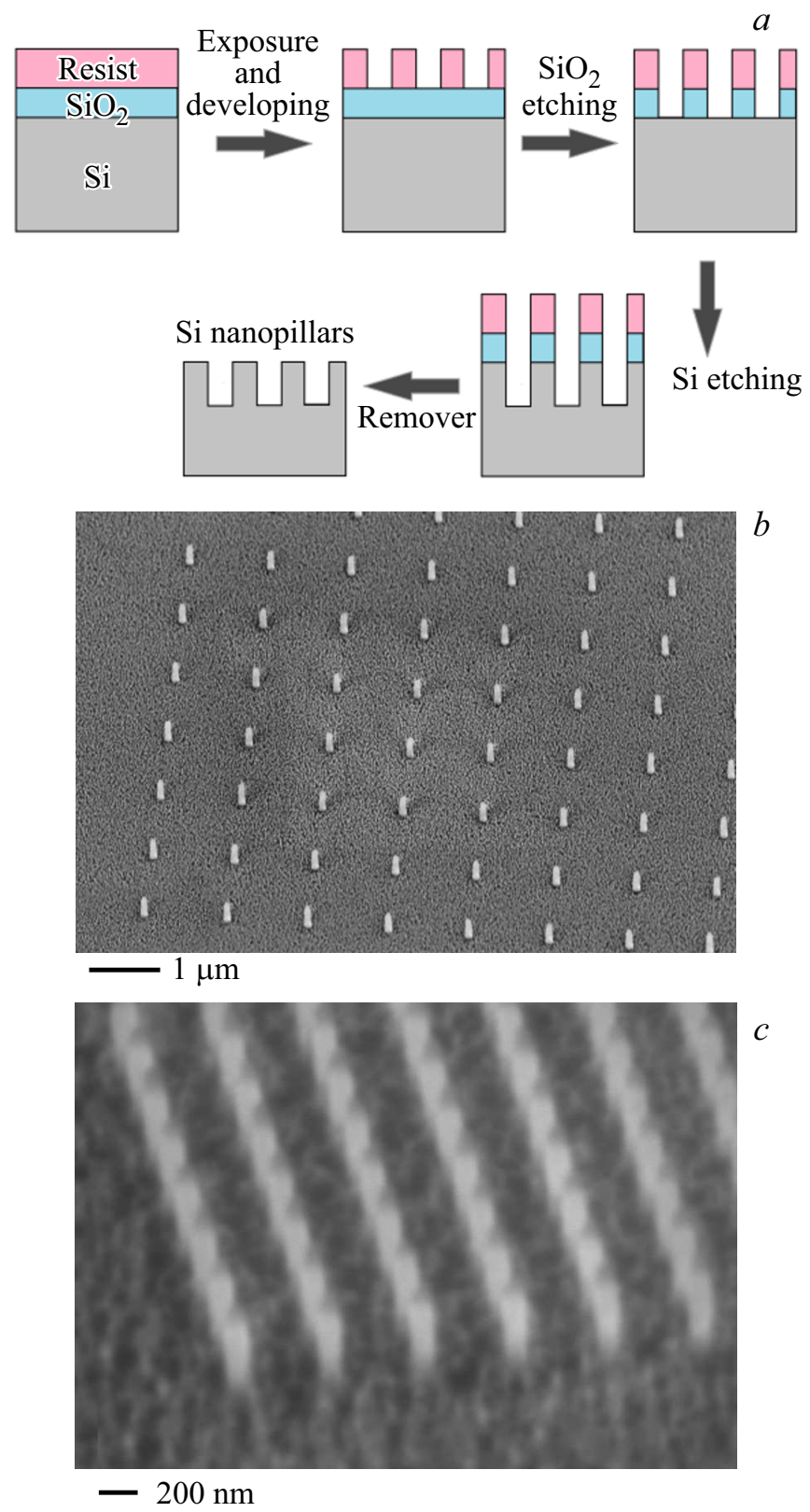

Рис. 1. $a-$ общая схема формирования структур. РЭМ изображения: $b-\mathrm{Si}$ НП после этапа травления $\mathrm{SiO}_{2}$ через маску из резиста, период 1200 нм, угол наклона $54^{\circ} ; c-\mathrm{Si} \mathrm{HП}$ после этапа травления $\mathrm{Si}$, период $500 \mathrm{Hм}$, угол наклона $60^{\circ}$.
Режимы плазменного травления структур

\begin{tabular}{c|c|c|c|c|c}
\hline Этап & $W, \mathrm{~B}$ T & $P$, Topp & $\mathrm{CF}_{4}, \%$ & $\mathrm{Ar}, \%$ & $\mathrm{CF}_{2} \mathrm{Cl}_{2}, \%$ \\
\hline Травление $\mathrm{SiO}_{2}$ & 180 & 250 & 12 & 12 & - \\
Травление $\mathrm{Si}$ & 200 & 250 & - & 25 & 9
\end{tabular}

ния в резисте проводилось в проявителе та D525 в течение 150 c. Затем осуществлялось реактивное ионное травление $\mathrm{SiO}_{2}$ через маску из резиста. После этого проводилось травление $\mathrm{Si}$ через маску из $\mathrm{SiO}_{2}$ и негативного резиста. В таблице приводятся режимы травления структур (мощность $W$, давление $P$, состав среды). Использовалась установка плазмохимического травления Matrix.

Спектры отражения $(R)$ от микромассивов $\mathrm{Si}$ НП измерялись в диапазоне длин волн от 400 до 1100 нм в линейно поляризованном свете вдоль оси нанопилларов. В качестве источника света использовалась галогеновая лампа накаливания. В качестве эталонного использовался сигнал, отраженный от зеркала с золотым покрытием. Схема установки для измерения отражения микромассивов приводится в работе [18].

\section{3. Результаты и обсуждение}

Нам неизвестны работы, где бы ранее проводилось травление структур $\mathrm{Si}$ НП через двойной слой, состоящий из негативного резиста и $\mathrm{SiO}_{2}$ толщиной 100 нм. Кроме этого мы экспериментально исследовали спектральные характеристики отражения Si HП, сформированных посредством данной методики. Важное преимущество данной методики заключается в том, что при экспонировании слоя резиста, находящегося на $\mathrm{SiO}_{2}$, происходит увеличение контраста резиста, так как уменьшается фоновая подсветка элементов резистивной маски. Это позволяет затем формировать структуры с большим аспектным отношением, расположенные в плотных массивах. Нами были сформированы структуры Si НП диаметром от 60 до 180 нм и высотой $350 \mathrm{Hм}$, период в квадратной решетке составлял 0.4-1.2 мкм. На рис. $1, b$ и $c$ приведены растровые электронномикроскопические (РЭМ) изображения микромассивов нанопилларов после травления $\mathrm{SiO}_{2}$ и $\mathrm{Si}$ соответственно.

На оптических изображениях в режиме светлого поля был явно виден структурный цвет микромассивов. Цвет Si НП изменялся в зависимости от их диаметра и периода. Затем были измерены спектры отражения сформированных микромассивов Si НП. На рис. 2 приводятся спектры отражения для микромассивов $\mathrm{Si}$ НП с периодом 500 и 600 нм. С уменьшением диаметра $(d)$ нанопилларов происходит смещение минимумов отражения в коротковолновую область (на рисунке отмечено стрелками). Измерение спектров отражения в области длин волн $<400$ нм ограничено спектром излучения используемой лампы. Однако из спектров отражения на 

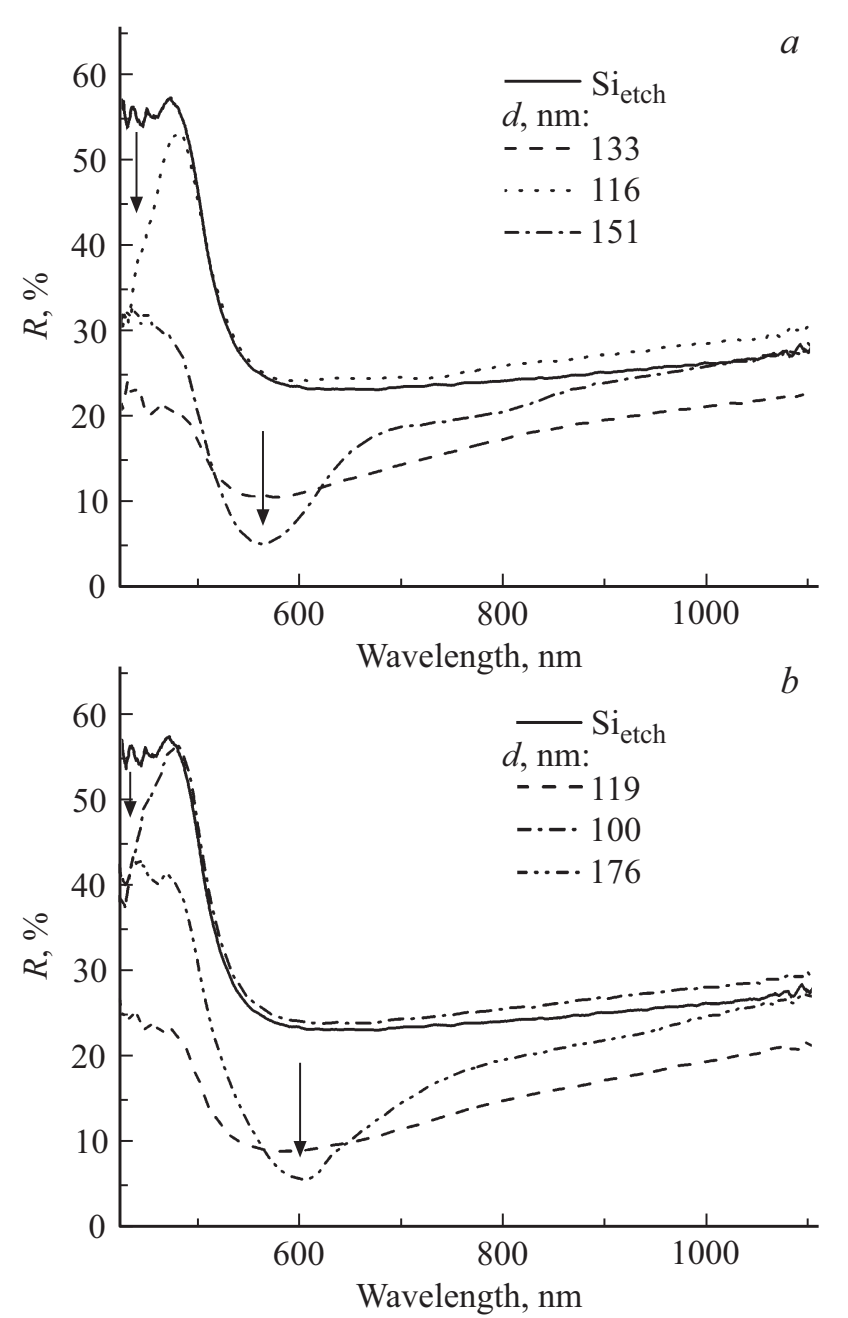

Рис. 2. Спектры отражения микромассивов $\mathrm{Si}$ НП с периодом $500(a)$ и $600 \mathrm{Hм}(b)$. Объектив Mituoyo $\times 50$, NA $0.42 . \mathrm{Si}_{\mathrm{etch}}-$ спектр для травленой поверхности кремния, измеренный рядом с Si НП. Стрелками отмечены минимумы коэффициента отражения.

рис. 2 видно, что в коротковолновой области происходит резкое увеличение коэффициента отражения. Так как исследуемые массивы $\mathrm{Si}$ НП представляют собой относительно неплотную структуру, то мы проводим сравнение спектров отражения $\mathrm{Si} \mathrm{HП} \mathrm{и} \mathrm{спектра} \mathrm{трав-}$ леной поверхности кремния $\mathrm{Si}_{\mathrm{etch}}$, измеренного вблизи микромассивов на образце. При этом коэффициент отражения от текстурированной при травлении поверхности кремния снижен по сравнению с объемным кремнием. Используя метод эллипсометрии, мы измерили эффективный показатель преломления травленой поверхности кремния, который составил 1.388 , а толщина текстурированного слоя составила 90 нм. На рис. 2 видно, что при уменьшении диаметра $\mathrm{Si}$ НП до $d=100 \mathrm{нм}$ на коротковолновом крае спектральной области измерений наблюдается резкое снижение коэффициента отражения. Таким образом, при уменьшении диаметра Si HП минимумы отражения сдвигаются в коротковолновую часть спектра, труднодоступную для измерения микроотражения в данной геометрии эксперимента. В измеренных спектрах отражения для микромассивов с периодом 800 и 1000 нм также фиксировался минимум отражения, положение которого зависело от диаметра Si НП. Однако из-за уменьшения количества $\mathrm{Si} \mathrm{HП}$, дающих вклад в отражение, происходило уменьшение эффекта резонансного отражения оптического излучения.

Хорошо известно, что сферические кремниевые наночастицы с геометрическими размерами в диапазоне 100-200 нм характеризуются сильным магнитным дипольным резонансом в видимом спектральном диапазоне (резонанс Ми) [19]. Оптические резонансы в спектрах отражения Si НП диаметром от 100 до 200 нм также сильно зависят от периода в массиве и высоты Si НП. Минимумы, которые фиксируются в экспериментальных спектрах, представленных на рис. 2, располагаются значительно левее, чем резонансы Ми, рассчитанные в [19]. Так, например, для периода 500 нм и диаметра $d=151$ нм, мода 1 резонанса Ми реализуется на длине волны $\lambda \approx 694 \mathrm{HM}$, а мода 2 реализуется на длине волны $\lambda \approx 415 \mathrm{Hм}$, однако в эксперименте резонанс наблюдается на длине волны $\lambda \approx 565 \mathrm{Hм}$ (рис. 2,a). Из рис. 2, $b$ видно, что резонанс наблюдается на длине волны $\lambda \approx 603$ нм, а из расчета следует, что мода 1 резонанса Ми должна проявляться на $\lambda \approx 787 \mathrm{HM}$, а мода $2-$ на длине волны $\lambda \approx 447$ нм. Несоответствие расчета резонансов Ми и эксперимента в квадратных матрицах кремниевых нанопилларов отмечалось в ряде работ $[15,18,20]$ и зависит от периода нанопилларов. Это несоответствие может быть вызвано интерференцией света, распространяющегося в подложке кремния [20].

Чтобы получить более узкие оптические резонансы в спектрах отражения, надо, по-видимому, формировать структуры Si HП с малой шероховатостью края. Также Si HП должны иметь строго вертикальные стенки, даже небольшая конусность структур влияет на механизм отражения света $\mathrm{Si} H$ П, происходит уширение минимумов в спектрах отражения. Оксидный слой нанометровой толщины на боковой поверхности $\mathrm{Si}$ НП также влияет на положение резонансов в спектрах отражения.

Также было исследовано влияние числовой апертуры объектива на полученные спектры отражения Si НП. На рис. 3 приводятся спектры отражения от микромассивов Si НП с периодом 500 и 600 нм, спектры измерены с помощью 2 объективов (Olympus $\times 10$, NA 0.25 и Mituoyo $\times 50$, NA 0.42). Перед оптическими измерениями маску из $\mathrm{SiO}_{2}$ не удаляли, так как при снятии $\mathrm{SiO}_{2}$ с поверхности нанопилларов может происходить увеличение шероховатости на краях боковых стенок нанопилларов.

При увеличении апертуры объектива коэффициент отражения в минимуме увеличивается: на рис. 3, $a$ отражение в минимуме увеличивается на $2.2 \%$, на рис. $3, b-$ на $1.2 \%$. Кроме того, так как падающий свет включает разные угловые компоненты, наблюдается сдвиг спектрального положения минимума отражения, 

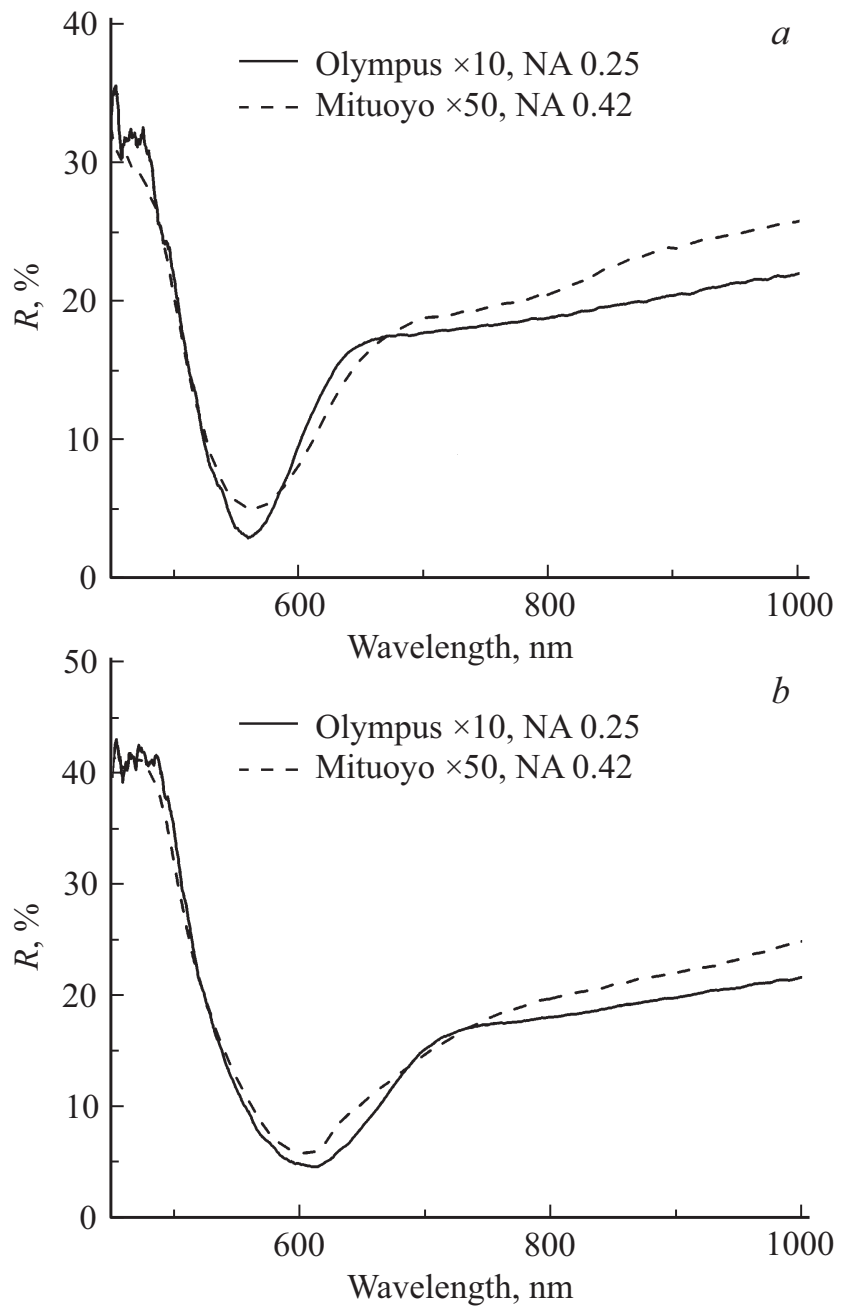

Рис. 3. Спектры отражения микромассивов Si HП: $a-$ период 500 нм, диаметр $151 \mathrm{Hм} ; b-$ период 600 нм, диаметр 176 нм. Объективы Olympus $\times 10$, NA 0.25 , и Mituoyo $\times 50$, NA 0.42 .

который также наблюдался в работе [11]. Это влияние следует учитывать при сравнении экспериментально измеренных спектров отражения с расчетными спектрами.

\section{4. Заключение}

В работе представлена методика формирования упорядоченных массивов $\mathrm{Si}$ НП посредством электроннолучевой литографии с использованием негативного электронного резиста с подслоем $\mathrm{SiO}_{2}$ и проведением последующего реактивного ионного травления монокристаллического кремния. Проведено экспериментальное исследование отражательных характеристик микромассивов Si HП, пространственно организованных в квадратную решетку. Спектры отражения от микромассивов $\mathrm{Si}$ НП измерялись в диапазоне длин волн от 400 до $1100 \mathrm{Hм}$ в линейно поляризованном свете. Свет падал перпендикулярно подложке. Спектры отражения структур имели один характерный минимум, причем положение миниму- ма отражения менялось с изменением диаметра Si HП. Также было исследовано влияние числовой апертуры объектива на измеренные спектры отражения Si HП.

Использование термического окисла кремния под электронным резистом при формировании микромассивов Si НП с периодом 500-600 нм позволяет уменьшить диаметр нанопилларов до 100 нм и менее, что приводит к смещению резонансного отражения света в ультрафиолетовую область спектра.

Авторы выражают благодарность Т.А. Гавриловой за помощь при проведении РЭМ-диагностики образцов. Работы по созданию образцов с микромассивами Si HП финансировались за счет гранта Российского научного фонда (проект № 14-22-00143). Исследование оптических свойств Si НП выполнено при финансовой поддержке РФФИ и правительства Новосибирской области в рамках научного проекта № 17-42-543293. Работы выполнялись с использованием оборудования ЦКП „Наноструктуры“. Работа выполнена при поддержке Министерства образования и науки РФ (проект 3.9787.2017/8.9).

\section{Список литературы}

[1] N. Dhindsa, J. Walia, S.S. Saini. Nanotechnology, 27 (49), 495203 (2016).

[2] K.T. Fountaine, W.S. Whitney, H.A. Atwater. J. Appl. Phys., 116, 153106 (2014).

[3] X. Li, J. Li, T. Chen, B.K. Tay, J. Wang, H. Yu. Nanoscale Res. Lett., 5 (11), 1721 (2010).

[4] M. Khorasaninejad, M.A. Swillam, K. Pillai, S.S. Saini. Optics Lett., 37 (20), 4194 (2012).

[5] S.-C. Yang, K. Richter, W.J. Fischer. Appl. Phys. Lett., 106, 081112 (2015).

[6] V. Flauraud, M. Reyes, R. Paniagua-Dominguez, A.I. Kuznetsov, J. Brugger. ACS Photonics, 4 (8), 1913 (2017).

[7] Y. Kanamori, T. Ozaki, K. Hane. Optical Rev., 21 (5), 723 (2014).

[8] T. Lee, J. Jang, H. Jeong, J. Rho. Nano Convergence, 5 (1), 1 (2018).

[9] B. Cheong, O.N. Prudnikov, E. Cho, H.-S. Kim, J. Yu, Y.-S. Cho, H.-Y. Choi, S.T. Shin. Appl. Phys. Lett., 94 (21), 213104 (2009).

[10] Y. Shen, V. Rinnerbauer, I. Wang, V. Stelmakh, J.D. Joannopoulos, M. Soljačić. ACS Photonics, 2 (1), 27 (2015).

[11] Y. Nagasaki, M. Suzuki, J. Takahara. Nano Lett., 17 (12), 7500 (2017).

[12] A.B. Evlyukhin, R.L. Eriksen, W. Cheng, J. Beermann, C. Reinhardt, A. Petrov, S. Prorok, M. Eich, B.N. Chichkov, S.I. Bozhevolnyi. Sci. Rep., 4, 4126 (2014).

[13] A.B. Evlyukhin, S.M. Novikov, U. Zywietz, R.L. Eriksen, C. Reinhardt, S.I. Bozhevolnyi, B.N. Chichkov. Nano Lett., 12, 3749 (2012).

[14] L.S. Golobokova, Yu.V. Nastaushev, F.N. Dultsev, D.V. Gulyaev, A.B. Talochkin, A.V. Latyshev. IOP J. Phys.: Conf. Ser., 541, 012074 (2014).

[15] Л.С. Голобокова, Ю.В. Настаушев, Ф.Н. Дульцев, Н.В. Крыжановская, Э.И. Моисеев, А.С. Кожухов, А.В. Латышев. ФТП, 49 (7), 961 (2015). 
[16] L.S. Basalaeva, Yu.V. Nastaushev, F.N. Dultsev. Materials Today: Proceedings, 4, 11341 (2017).

[17] B. Hamza, A. Kadiyala, L.A. Hornak, Y. Liu, J.M. Dawson. Microelectronic Engin., 91, 70 (2012).

[18] Л.С. Басалаева, Ю.В. Настаушев, Ф.Н. Дульцев, Н.В. Крыжановская, Э.И. Моисеев. Опт. и спектр., 124 (5), 695 (2018).

[19] A.I. Kuznetsov, A.E. Miroshnichenko, Y.H. Fu, Jing Bo Zhang, B. Luk'yanchuk. Sci. Rep., 2, 492 (2012).

[20] F.J. Bezares, J.P. Long, O.J. Glembocki, J. Guo, R.W. Rendell, R. Kasica, L. Shirey, J.C. Owrutsky, J.D. Caldwell. Opt. Express, 21 (23), 27587 (2013).

Редактор Л.В. Шаронова

\title{
Silicon nanopillars microarrays: \\ the formation and resonance reflection of the light
}

\author{
L.S. Basalaeva ${ }^{1}$, Yu.V. Nastaushev ${ }^{1}$, F.N. Dultsev ${ }^{1,2}$, \\ N.V. Kryzhanovskaya ${ }^{3}$, E.I. Moiseev ${ }^{3}$ \\ ${ }^{1}$ Rzhanov Institute of Semiconductor Physics, \\ Siberian Branch of Russian Academy of Sciences, \\ 630090 Novosibirsk, Russia \\ ${ }^{2}$ Novosibirsk State University, \\ 630090 Novosibirsk, Russia \\ ${ }^{3}$ St. Petersburg National Research \\ Academic University, \\ Russian Academy of Sciences, \\ 194021 St. Petersburg, Russia
}

\begin{abstract}
The results of the investigation of silicon nanopillar microarrays reflectance spectral characteristics are presented. Electron-beam lithography on the negative electron resist and reactive ion etching were used for formation of $\mathrm{Si}$ nanopillars. $\mathrm{Si}$ nanopillars were etched using the negative electron resist and $100 \mathrm{~nm} \mathrm{SiO} \mathrm{S}_{2}$ as a mask. The measured reflectance spectra exhibited minima. The reflectance minimum position depends strongly on the Si nanopillar diameter.
\end{abstract}

